\title{
Genome-wide case-control study of musculoskeletal adverse events and functional genomics in women receiving aromatase inhibitors: going beyond associations
}

James N Ingle*

\section{Introduction}

In postmenopausal women with early breast cancer, the third-generation aromatase inhibitors (AIs; anastrozole, exemestane, and letrozole) have been proven to be of value in multiple large well-conducted clinical trials as initial adjuvant endocrine therapy, after several years of tamoxifen, and as extended adjuvant endocrine therapy after about 5 years of tamoxifen [1-8]. A recent American Society of Clinical Oncology clinical practice guideline stated that an AI should be used in the adjuvant setting either initially or after some period of tamoxifen therapy [9].

Despite the proven value of the AIs, many women are not adherent [10]. About one-half of women treated with an AI have new or worsening joint complaints [11]. The importance of musculoskeletal complaints was identified in reviewing the experience with MA.27, a large phase III trial comparing the non-steroidal $\mathrm{AI}$ anastrozole with the steroidal AI exemestane as adjuvant therapy for early breast cancer. These musculoskeletal adverse events (MS-AEs) were the most common reason why patients discontinued AI therapy. We had previously demonstrated marked variability in metabolism and pharmacodynamics of one of the AIs, anastrozole [12]. We hypothesized that the variability seen with respect to MS-AEs in women treated with anastrozole or exemestane on MA.27 could be related to genetic variability of the patients. We proceeded to perform a genome-wide association study (GWAS) aimed at identifying SNPs associated with MS-AEs. The results of this GWAS and the functional genomic laboratory studies performed have recently been published [13]. This short communication summarizes the highlights of this work plus a commentary on future pharmacogenomic studies of anticancer agents.

*Correspondence: ingle.james@mayo.edu

Mayo Clinic, 200 First Street SW, Rochester, MN 55905, USA

Biomed Central @ 2010 Biomed Central Ltd

\section{Methods}

MA.27 is a randomized clinical trial conducted by the Breast Cancer Intergroup of North America that was coordinated by the NCIC Clinical Trials Group [13]. Eligible patients were those with a postmenopausal status and resected American Joint Committee on Cancer (version 6) stage I to III breast cancer that was hormone receptor positive. Patients were randomized to anastrozole or exemestane for a period of 5 years. A total of 6,827 women in North America were randomized and the majority provided DNA and consent for its use in genetic studies.

Cases were defined as those patients who developed a MS-AE, as previously defined [13], and each case was matched to two controls. The design utilized was a nested matched case-control study and the primary analyses were based on conditional logistic regression. The RIKEN Center for Genomic Medicine performed genotyping with the Illumina Human610-Quad platform. Imputation and fine mapping were performed in the region of interest on chromosome 14 containing the SNPs with the smallest $P$ values. Functional genomic studies, relating to the SNPs on chromosome 14, were performed using electrophoretic motility shift (EMS) assays, chromatin immunoprecipitation (ChIP) assays, and transfection studies.

\section{Results}

We studied 293 cases and 585 controls, and cases and controls were well balanced for all factors except prior hormone replacement therapy, which was significantly higher in cases than controls (66\% versus 44\%), and fractures within the past 10 years, which were slightly higher in cases than controls (13\% versus 9\%). A total of 551,395 SNPs were used in the association analyses after exclusion of genotype failures $(\mathrm{n}=11,281)$, SNPs with a minor allele frequency $<0.01(\mathrm{n}=29,478)$, and SNPs with a departure $(P<1 \mathrm{E}-06)$ from Hardy-Weinberg equilibrium $(\mathrm{n}=82)$. The conditional logistic regression analyses were adjusted for population stratification and revealed three SNPs (rs7158782, rs7159713, rs2369049) on chromosome 
14 in high linkage disequilibrium with the smallest $P$ values (7.74E-07 to 2.23E-06), which approach the Bonferroni threshold of 1E-07. Subsequently, imputation and fine mapping revealed an additional SNP (rs11849538), also on chromosome 14 and in high linkage disequilibrium with the three genotyped SNPS, with the smallest $P$-value (6.67E-07). These four SNPs were all found to be close (that is, within 7,109 bp) of the 3' end of the T-cell leukemia 1A (TCL1A) gene with the closest SNP (rs11849538) being only 926 bp away.

Initially, we determined that TCL1A is variably expressed in 288 lymphoblastoid cell lines from three different ethnic groups for which we have expression array and genome-wide SNP data. Functional genomic studies were performed with the three genotyped SNPs and the one imputed/fine mapped SNP to examine for any functional significance. Lymphoblastoid cell nuclear extract used in EMS assays showed a 'shift', that is, protein binding, for three of the SNPs (rs11849538, rs7158782, rs7159713) with less binding by the variant than wild-type sequences. Of particular interest as it relates to a drug that lowers estrogen levels, a TRANSFAC database search predicted that the SNP (rs11849538) with the smallest $P$-value would create an estrogen response element and this was confirmed with a ChIP assay utilizing lymphoblastoid cells with known genotype for this SNP that had been transfected with estrogen receptor (ER) $\alpha$. TCL1A expression was linked to estrogen by exposing U20S cells that had been stably transfected with $\mathrm{ER} \alpha$ or $\mathrm{ER} \beta$ to $0.1 \mathrm{nM} \mathrm{E2}$, and demonstrating eightand six-fold increases in TCL1A mRNA expression after 18 hours and 1 hour, respectively. To determine the effect of these four SNPs on estrogen-dependent TCL1A expression, lymphoblastoid cell lines with genotypes known for the four SNPs were transiently transfected with $\mathrm{ER} \alpha$ and exposed to various concentrations of estradiol. All three ethnic groups showed greater TCL1A expression with the variant than the wild-type sequence. Because the clinical picture of the MS-AEs is reminiscent of a chronic inflammatory state, we utilized the same 288 lymphoblastoid cell lines noted above and determined the correlation between TCL1A expression and expression of IL17 and the IL17 receptor A (IL17RA). Remarkably, TCL1A and IL7RA expression were highly correlated $(P<1$.9E-10). In studies using U20S cells transfected with either ER $\alpha$ or ER $\beta$, small interfering RNA (siRNA) knockdown of TCL1A resulted in decreased expression of IL17RA but increased expression of IL17, whereas TCL1A overexpression resulted in increased IL17RA expression and decreased expression of IL17.

\section{Discussion}

We identified four SNPs on chromosome 14 that were associated with MS-AEs in women receiving AIs as adjuvant therapy for early-stage breast cancer. Given that AIs perturb estrogen levels in these women, we examined the relationship between the SNPs and estrogen action. Of particular note is that the SNP with the smallest $P$ value (rs11849538) created an estrogen response element that was shown by ChIP assay to be functional. Estrogens induced TCL1A expression that was significantly higher in cells with the variant SNPs than those with the wildtype sequence. Expression of TCL1A was directly associated with IL17RA expression in that siRNA knockdown of TCL1A resulted in decreased expression of IL17RA and increased expression of IL17 whereas overexpression of TCL1A resulted in increased expression of IL17RA and decreased expression of IL17.

The identification of a relationship between TCL1A expression and the inflammatory cytokine IL17 is particularly noteworthy given the recent identification of a third lineage of T-helper cells (in addition to Th1 and Th2), that is, Th17, that is associated with chronic inflammation [14], and in which IL17 plays a central role. IL17 and IL17RA represent potential targets and efforts to target these factors in a variety of inflammatory diseases are in progress (reviewed in [14]).

The study reported here demonstrates the value of GWASs. A GWAS is, by definition, a 'hypothesis-free' interrogation of the entire genome and, in our study, identified a gene, TCL1A, which was totally unexpected. However, it was clearly necessary to perform the functional genomic studies to begin to understand the potential biologic implications of these findings. Clearly, replication is an important consideration in the performance of a GWAS because of the problem of false positive associations [15]. The replication of genomewide pharmacogenomic studies of anti-cancer agents will likely be found to be substantially more problematic than genome-wide studies examining risk of developing a cancer. For example, in a recent study to identify breast cancer susceptibility alleles, a GWAS was performed in 3,659 cases and 4,897 controls, and then promising associations were then studied in 12,576 cases and 12,223 controls [16]. In the case of pharmacogenomic studies of anti-cancer agents, a GWAS will likely be best conducted utilizing patients entered into a prospectively conducted clinical trial. MA.27, the study from which the patients in our GWAS were obtained, is such a trial but is the largest study conducted of AIs alone, taking 8 years to complete at a cost of tens of millions of dollars. Replication will not be possible utilizing a larger cohort of patients as it simply does not exist. Although the conduct of rigorous and insightful functional genomic studies can be viewed as important in pursuing leads from any GWAS, such studies may have greater importance in the case of anticancer agents because of limitations imposed by a relative paucity of patient cohorts, at least compared to studies 
examining risk, that is, genetic predisposition, of developing cancer.

In conclusion, our GWAS identified four SNPs related to MS-AEs in women receiving AIs as adjuvant therapy for their early breast cancer. These SNPs were related to $T C L 1 A$, which in turn was related to the inflammatory cytokine IL17. Further work is ongoing in our laboratory to expand our understanding of the mechanisms involved in the TCL1A-IL17 relationship. Ultimately, this new knowledge should help identify means to ameliorate the AI-related MS-AEs in order to allow more women with early breast cancer to take these potentially life-saving drugs.

\section{Abbreviations}

$\mathrm{Al}$, aromatase inhibitor; bp, base pair; ChIP, chromatin immunoprecipitation; EMS, electrophoretic motility shift; ER, estrogen receptor; GWAS, genomewide association study; IL, interleukin; IL17RA, IL17 receptor A; MS-AE, musculoskeletal adverse event; siRNA, small interfering RNA; SNP, single nucleotide polymorphism.

\section{Competing interests}

The author declares that he has no competing interests.

\section{Acknowledgments}

Supported in part by NIH grants U01GM61388, U01GM63173, P50CA116201, U10CA77202, CCS 015469 from the Canadian Cancer Society, the Biobank Japan Project funded by the Ministry of Education, Culture, Sports, Science and Technology, Japan, and the Breast Cancer Research Foundation. The MA.27 trial, from which the patients in this study were obtained, was supported in part by Pfizer, Inc.

This article has been published as part of Breast Cancer Research Volume 12 Supplement 4, 2010: Controversies in Breast Cancer 2010. The full contents of the supplement are available online at http://breast-cancer-research.com/ supplements/12/S4

Published: 20 December 2010

\section{References}

1. The Arimidex, Tamoxifen, Alone or in Combination (ATAC) Trialists' Group: Effect of anastrozole and tamoxifen as adjuvant treatment for early-stage breast cancer: 100-month analysis of the ATAC trial. Lancet Oncol 2008, 9:45-53.

2. Coates AS, Keshaviah A, Thürlimann B, Mouridsen H, Mauriac L, Forbes, JF, Paridaens R, Castiglione-Gertsch M, Gelber RD, Colleoni M, Láng I, Del Mastro L, Smith I, Chirgwin J, Nogaret J-M, Pienkowski T, Wardely A, Jakobsen EH, Price KN, Goldhirsch A: Five years of letrozole compared with tamoxifen as initial adjuvant therapy for postmenopausal women with endocrineresponsive early breast cancer: update of study BIG 1-98. J Clin Oncol 2007, 25:486-492

3. Coombes RC, Kilburn LS, Snowdon CF, Paridaens R, Coleman RE, Jones SE, Jassem J, Van de Velde CJH, Delozier T, Alvarez I, Del Mastro L, Ortmann O, Diedrich K, Coates AS, Bajetta E, Holmberg SB, Dodwell D, Mickiewicz E, Andersen J, Lǿnning PE, Cocconi G, Forbes J, Castiglione M, Stuart N, Stewart A, Fallowfield LJ, Bertelli G, Hall E, Bogle RG, Carpentieri M, et al.: Intergroup Exemestane Study. Survival and safety of exemestane versus tamoxifen after 2-3 years' tamoxifen treatment (Intergroup Exemestane Study): a randomised controlled trial. Lancet 2007, 369:559-570.

4. Jakesz R, Jonat W, Gnant M, Mittlboeck M, Greil R, Tausch C, Hilfrich J, Kwasny W, Menzel C, Samonigg H, Seifert M, Gademann G, Kaufmann M, on behalf of the ABCSG and the GABG: Switching of postmenopausal women with endocrine-responsive early breast cancer to anastrozole after 2 years' adjuvant tamoxifen: combined results of ABCSG trial 8 and ARNO 95 trial. Lancet 2005, 366:455-462.
5. Boccardo F, Rubagotti A, Guglielmini P, Fini A, Paladini G, Mesiti M, Rinaldini M, Scali S, Porpiglia M, Benedetto C, Restuccia N, Buzzi F, Franchi R, Massidda B, Distante V, Amadori D, Sismondi P: Switching to anastrozole versus continued tamoxifen treatment of early breast cancer. Updated results of the Italian tamoxifen anastrozole (ITA) trial. Ann Oncol 2006, 17(Suppl 7):vii10-4.

6. Kaufmann M, Jonat W, Hilfrich J, Eidtmann H, Gademann G, Zuna I, von Minckwitz G: Improved overall survival in postmenopausal women with early breast cancer after anastrozole initiated after treatment with tamoxifen compared with continued tamoxifen: The ARNO 95 study. J Clin Oncol 2007, 25:2664-2670.

7. Goss PE, Ingle JN, Martino S, Robert NJ, Muss HB, Piccart MJ, Castiglione M, Tu DS, Shepherd LE, Pritchard Kl, Livingston RB, Davidson NE, Norton L, Perez EA Abrams JS, Cameron DA, Palmer MJ, Pater JL: Randomized trial of letrozole following tamoxifen as extended adjuvant therapy in receptor-positive breast cancer: updated findings from NCICCTG MA.17. J Nat/ Cancer Inst 2005, 97:1262-1271.

8. Mamounas EP, Jeong J-H, Wickerham DL, Smith RE, Ganz PA, Land SR, Eisen A, Fehrenbacher L, Farrar WB, Atkins JN, Pajon ER, Vogel VG, Kroener JF, Hutchins LF, Robidoux A, Hoehn JL, Ingle JN, Geyer CE Jr, Costantino JP, Wolmark N: Benefit from exemestane as extended adjuvant therapy after 5 years of adjuvant tamoxifen: intention-to-treat analysis of the National Surgical Adjuvant Breast and Bowel Project B-33 trial. J Clin Oncol 2008, 26:1965-1971.

9. Burstein HJ, Prestrud AA, Seidenfeld J, Anderson H, Buchholz TA, Davidson NE, Gelmon KE, Giordano SH, Hudis CA, Malin J, Mamounas EP, Rowden D, Solky AJ, Sowers MR, Stearns, V, Winer EP, Somerfield MR, Griggs JJ: American Society of Clinical Oncology clinical practice guidelines: update on adjuvant endocrine therapy for women with hormone receptor-positive breast cancer. J Clin Oncol 2010, 28:3784-3796.

10. Partridge AH, LaFountain A, Mayer E, Taylor BS, Winer E, Asnis-Alibozek A: Adherence to initial adjuvant anastrozole therapy among women with early-stage breast cancer. J Clin Oncol 2008, 26:556-562.

11. Crew KD, Greenlee H, Capodice J, Raptis G, Brafman L, Fuentes D, Sierra A, Hershman DL: Prevalence of joint symptoms in postmenopausal women taking aromatase inhibitors for early-stage breast cancer. J Clin Oncol 2007, 25:3877-3883.

12. Ingle JN, Buzdar AU, Schaid DJ, Goetz MP, Batzler A, Robson ME, Northfelt DW, Olson JE, Perez EA, Desta Z, Weintraub RA, Williard CV, Flockhart DA, Weinshilboum RM: Variation in anastrozole metabolism and pharmacodynamics in women with early breast cancer. Cancer Res 2010, 70:3278-3286.

13. Ingle, JN, Schaid DJ, Goss PE, Liu M, Mushiroda T, Chapman J-AW, Kubo M, Jenkins GD, Batzler A, Shepherd L, Pater J, Wang L, Ellis MJ, Stearns V, Rohrer DC, Goetz MP, Pritchard KI, Flockhart DA, Nakamura Y, Weinshilboum RM: Genome-wide associations and functional genomic studies of musculoskeletal adverse events in women receiving aromatase inhibitors. J Clin Oncol 2010, 28:4674-4682.

14. Miossec P, Korn T, Kuchroo VK: Interleukin-17 and type 17 helper cells. NEngl J Med 2009, 361:888-898.

15. Pearson TA, Manolio T: How to interpret a genome-wide association study. JAMA 2008, 299:1335-1344.

16. Turnbull C, Ahmed S, Morrison J, Pernet D, Renwick A, Maranian M, Seal S, Ghoussaini M, Hines S, Healey CS, Hughes D, Warren-Perry M, Tapper W, Eccles D, Evans DG, The Breast Cancer Susceptibility Collaboration (UK), Hooning M, Schutte M, van den Ouweland A, Houlston R, Ross G, Langford C, Pharoah PDP, Stratton MR, Dunning AM, Rahman N, Easton DF: Genomewide association study identifies five new breast cancer susceptibility loci. Nat Genet 2010, 42:504-507.

\section{doi:10.1186/bcr2746}

Cite this article as: Ingle JN: Genome-wide case-control study of musculoskeletal adverse events and functional genomics in women receiving aromatase inhibitors: going beyond associations. Breast Cancer Research 2010, 12(Suppl 4):S17. 